\section{Root-zone Alcohol Is an Effective Growth Retardant for Paperwhite Narcissus}

\author{
William B. Miller and Erin Finan
}

AdDitionAl INDEX wORDs. ethanol, flower bulbs, forcing, height control

\begin{abstract}
Summary. Ethanol was demonstrated to reduce unwanted floral scape and leaf elongation of 'Ziva' paperwhite narcissus (Narcissus tazetta) when plants were grown with traditional pebble culture. Root-zone ethanol concentrations of $1 \%$ to $5 \%(\mathrm{v} / \mathrm{v})$ were effective in reducing height without visible phytotoxicity to the roots. Various ethanol sources, including gin, vodka, whiskey, schnapps, rum, and tequila, were equally effective in reducing growth when supplied at 4\%; peppermint schnapps caused somewhat more growth inhibition, providing a safe, effective, and organic method for amateurs to control height of this popular flowering bulb. Beer and wine (white or red) were unsuitable for this use at $4 \%$ alcohol concentration.
\end{abstract}

$\mathrm{P}$ aperwhite narcissus is traditionally grown hydroponically by planting the bulbs (which do not require a cold period to flower) into shallow dishes with pebbles, decorative glass beads, etc. The bulbs root and grow rapidly, and are often flowering within 3 weeks of planting. One of the issues for homeowners is that the plants grow quite tall and floppy in the interior environment, detracting from the aesthetic value of the plant (Land, 2005).

An inquiry from the New York Times (Land, 2005) prompted us to investigate the possibility of using dilute alcohol as a growth retardant in paperwhite narcissus. A Times reader wrote to the garden editor, stating they "kept hearing that adding gin to paperwhites...would keep them from growing tall and floppy..." The reader claimed to have tried this, with success, and wondered whether an "essential oil" in the gin might be responsible. The purpose of the research presented here was to demonstrate the feasibility of using of ethanol as a growth retardant on paperwhite narcissus. Rather than gin, we initially focused on ethanol to establish the lack of an effect of "essential oils," then conducted an experiment using different

Department of Horticulture, Cornell University, Ithaca, NY 14853.

Use of trade names does not imply endorsement of the products named or criticism of similar ones not named. We are grateful to the Royal Dutch Wholesalers' Association for flower bulbs and nursery stock; the North American Flowerbulb Wholesalers' Association for financial assistance with this research; and Jan Doornbosch, International Bulb Company, Montvale, N.J., for donating the bulbs. consumer-available ethanol sources to broadly demonstrate the utility of this technique.

\section{Materials and methods}

Two experiments were conducted to evaluate the effect of alcohol on height of 'Ziva' paperwhite narcissus. Bulbs (obtained from a commercial source) were planted in non-draining Styrofoam cups using washed marble gravel $(0.5-\mathrm{cm}$ mesh), then placed inside $10-\mathrm{cm}$-diameter plastic pots for rigidity. Tap water was provided to initiate root growth, and grown in a glass greenhouse with temperatures of $17^{\circ} \mathrm{C}$ day and night. After 7 to $10 \mathrm{~d}$, roots were well established and shoots were growing 3 to $6 \mathrm{~cm}$ above the top of the bulb.

In the first experiment, the water was decanted and replaced with ethanol with concentrations of $0 \%$ (water control), $1 \%, 5 \%, 10 \%$, and $25 \%(\mathrm{v} / \mathrm{v})$. The root-zone solution was replenished with the appropriate alcohol solution on an as-needed basis. This experiment was repeated two times. ducted to evaluate the effect of alcohol source on reduction of height growth. A series of commercial ethanol products, including London dry gin (Tanqueray; Charles Tanqueray \& Co., Amsterdam, The Netherlands), unflavored vodka (Absolut; V\&S
A second experiment was con-
Vin \& Spirits, Stockholm, Sweden), Tennessee whiskey [Jack Daniel's (black label); Jack Daniel Distillery, Lynchburg, Tenn.], unflavored white rum (Bacardi Superior; Bacardi USA, Miami), gold tequila (Jose Cuervo Especial; Heublein, Norwalk Conn.), mint schnapps (Dr. McGillicuddy's Mentholmint; Sazerac Co. Inc., New Orleans), economy-grade French red wine (Cabernet Sauvignon; Domaine Caton, Monsieur Touton Selections Ltd., New York), economy-grade California white wine (Chardonnay; Peter Vella Wines, Modesto, Calif.), and pale lager beer (Heineken; Heineken N.V., Amsterdam, The Netherlands) were diluted to give final concentration of $4 \%(\mathrm{v} / \mathrm{v})$ ethanol. These alcohols were applied as in the first experiment.

Plants were measured (pot rim to the top of the tallest leaf and top of the flower bud or open flower) every 2 or $3 \mathrm{~d}$ during each experiment. Observations were made of flower opening, flower size, and flower longevity. Each experiment was conducted as a completely randomized design with eight replications (plants) per treatment.

\section{Results and discussion}

Ethanol was an effective growth regulator when applied to the root zone of paperwhite narcissus growing in traditional pebble culture (Fig. 1). Ethanol reduced growth of leaves and stems soon after introduction to the root zone (Figs. 2 and 3), and this reduction was greater as alcohol concentration increased. When applied at concentrations of $10 \%$ or more, ethanol was toxic, as indicated by extreme stunting, flower shriveling, and root necrosis (Fig. 1). General observations indicated that within 2-3 dexposure to $25 \%$ root-zone ethanol, plants showed visible loss of turgor, followed $1-3 \mathrm{~d}$ later by plants in the $10 \%$ ethanol treatment. With $10 \%$ ethanol, the onset of flower opening was initially normal, but flower size was greatly reduced (about $50 \%$ of normal size). Both $10 \%$ and $25 \%$ ethanol caused premature flower senescence.

Plants grown in $1 \%$ or $5 \%$ ethanol appeared normal in all respects except that leaves and stems were shorter than

\begin{tabular}{llll}
\hline $\begin{array}{l}\text { Units } \\
\begin{array}{l}\text { To convert U.S. to SI, } \\
\text { multiply by }\end{array}\end{array}$ & U.S. unit & SI unit & $\begin{array}{l}\text { To convert SI to U.S., } \\
\text { multiply by }\end{array}$ \\
\hline 2.54 & inch $(\mathrm{es})$ & $\mathrm{cm}$ & 0.3937 \\
$\left({ }^{\circ} \mathrm{F}-32\right) \div 1.8$ & ${ }^{\circ} \mathrm{F}$ & ${ }^{\circ} \mathrm{C}$ & $\left(1.8 \times{ }^{\circ} \mathrm{C}\right)+32$
\end{tabular}



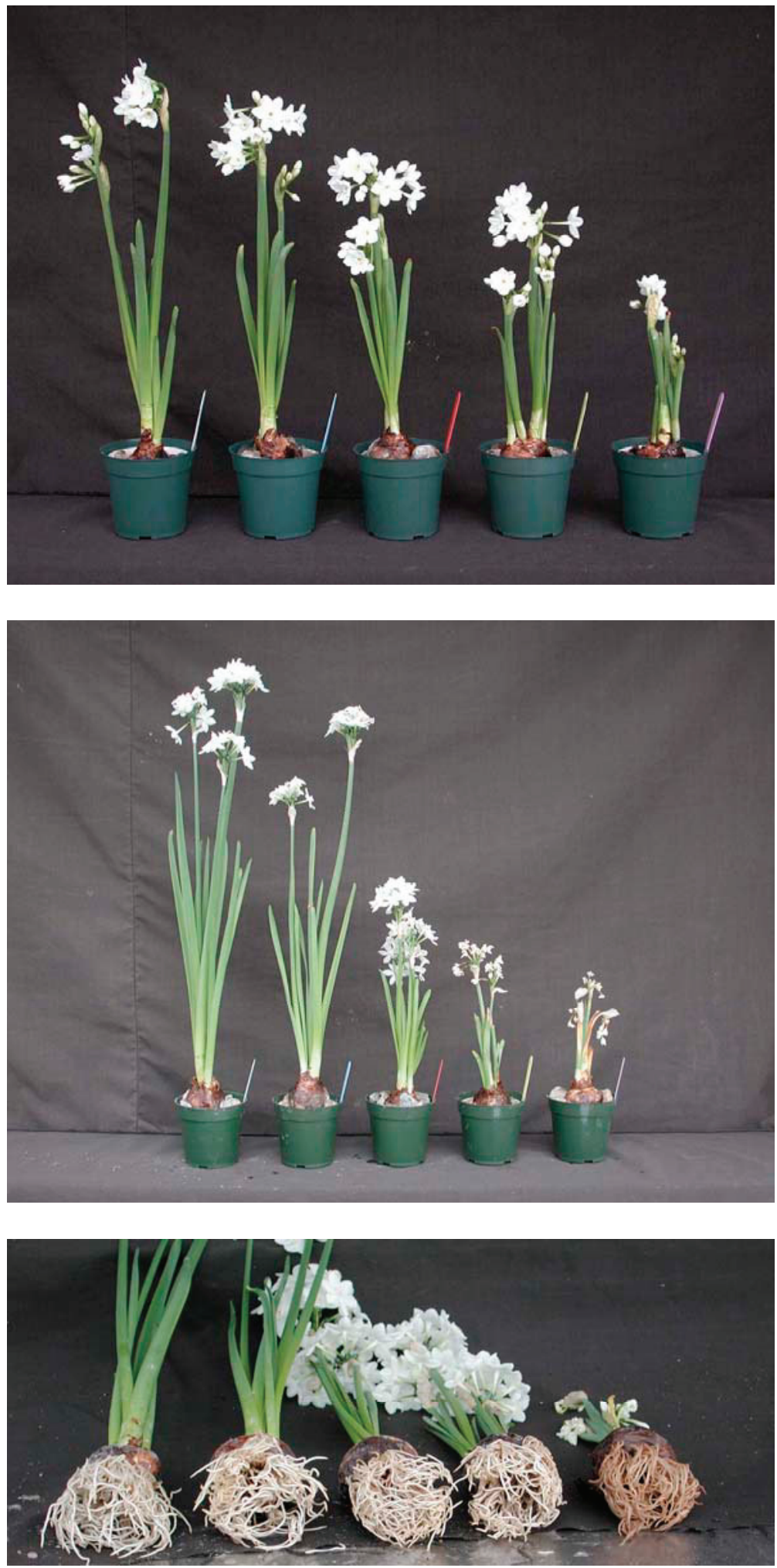

Fig. 1. Appearance of 'Ziva' paperwhite narcissus plants and roots when grown with differing ethanol concentrations in the root zone. Plants were initially grown in tap water until the shoots were 3 to $6 \mathrm{~cm}$ long. The water was decanted and the indicated ethanol solutions were the used as needed for irrigation. Left to right: control (water), $1 \%, 5 \%, 10 \%$, and $25 \%$ ethanol. Top panel: at the start of flowering. Middle and bottom panels: at full flower, of plants and roots, respectively.

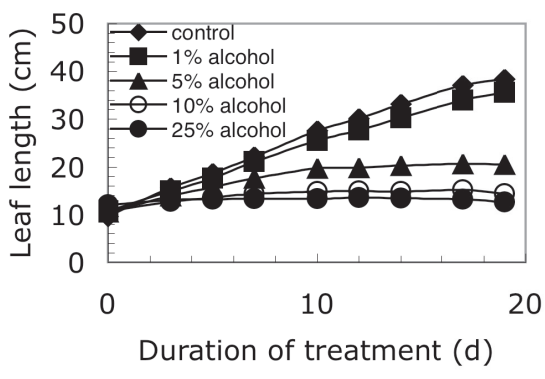

Fig. 2. Effect of root-zone ethanol on leaf growth of 'Ziva' paperwhite narcissus. Plants were initially grown in tap water, then the indicated ethanol solutions were used for irrigation beginning on day $0(1 \mathrm{~cm}=0.3937$ inch).

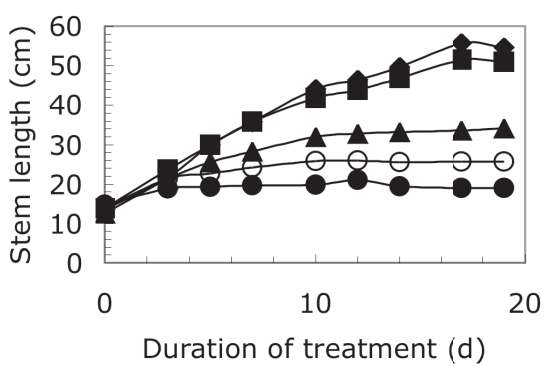

Fig. 3. Effect of root-zone ethanol on stem growth of 'Ziva' paperwhite narcissus. Plants were initially grown in tap water, then the indicated ethanol solutions were used for irrigation beginning on day $0(1 \mathrm{~cm}=0.3937$ inch).

controls (Table 1). Flowering date and flower size and longevity were unaffected by $1 \%$ to $5 \%$ root-zone ethanol (data not shown); all of these observations were also made in subsequent experiments. These results show that dilute root-zone ethanol can be a useful material for reducing growth of paperwhite narcissus.

Since homeowners typically do not have access to pure ethanol, we conducted additional experiments to evaluate the effect of ethanol source. In the New York Times question, the reader hypothesized an effect of "some essential oil" in the gin. Therefore, we evaluated a series of consumable alcohols available to homeowners, each diluted to give a final ethanol concentration of $4 \%$, based on favorable results from the first experiments. The results indicated that the "hard liquors" tested were equally effective in suppressing paperwhite narcissus 
Table 1. Root-zone ethanol effects on leaf and stem length at full flower. Bulbs were initially grown in tap water for $7 \mathrm{~d}$, then water poured off. Then, ethanol at the indicated concentrations (by volume) was used as the irrigation solution until flowering.

\begin{tabular}{lcc}
\hline \multirow{2}{*}{$\begin{array}{l}\text { Ethanol } \\
\text { concn }\end{array}$} & \multicolumn{2}{c}{$\begin{array}{c}\text { Length }(\mathrm{cm}) \\
\text { at full flower }\end{array}$} \\
\cline { 2 - 3 } & Leaves & Stems \\
\hline 0 (water control) & $38.4 \mathrm{a}$ & $55.7 \mathrm{a}$ \\
$1 \%$ & $35.6 \mathrm{~b}$ & $51.6 \mathrm{~b}$ \\
$5 \%$ & $20.5 \mathrm{c}$ & $33.6 \mathrm{c}$ \\
$10 \%$ & $14.4 \mathrm{~d}$ & $25.8 \mathrm{~d}$ \\
$25 \%$ & $12.6 \mathrm{~d}$ & $19.0 \mathrm{e}$ \\
\hline
\end{tabular}

${ }^{2}$ Data are means of eight plants per treatment; mean separation in columns by Student-Newman-Keuls; 1 $\mathrm{cm}=0.3937$ inch

leaf and stem growth when provided at a constant ethanol concentration, while the schnapps caused a somewhat greater reduction in growth (Table 2 ). Beer and wine (red or white) caused dramatic phytotoxicity and encouraged apparent microbial growth, leading to severely stunted, unhealthy plants (Table 2).

The findings presented in this paper support the notion that dilute root-zone ethanol solutions could be useful for homeowners to reduce excessive leaf and flower stem elongation when forcing paperwhite narcissus in
Table 2. Root-zone ethanol effects on leaf and stem length at full flower of 'Ziva' paperwhite narcissus. Bulbs were initially grown in tap water for 7 $d$, then poured off. Then, the indicated alcohols [each at $4 \%(v / v)$ final concentration] were used as the irrigation solution until full flowering.

\begin{tabular}{llr}
\hline \multirow{2}{*}{$\begin{array}{l}\text { Ethanol } \\
\text { concn }\end{array}$} & \multicolumn{2}{c}{$\begin{array}{c}\text { Length }(\mathrm{cm}) \\
\text { at full }\end{array}$} \\
\cline { 2 - 3 } Llower & Leaves & Stems \\
\hline Control & $36.5 \mathrm{a}$ & $58.0 \mathrm{a}$ \\
Ethanol & $26.3 \mathrm{de}$ & $40.0 \mathrm{c}$ \\
Gin & $28.5 \mathrm{~cd}$ & $42.0 \mathrm{c}$ \\
Rum & $27.2 \mathrm{cde}$ & $42.2 \mathrm{c}$ \\
Schnapps & $19.6 \mathrm{f}$ & $38.8 \mathrm{c}$ \\
Tequila & $26.0 \mathrm{de}$ & $40.2 \mathrm{c}$ \\
Vodka & $25.3 \mathrm{de}$ & $39.8 \mathrm{c}$ \\
Whiskey & $25.5 \mathrm{de}$ & $41.2 \mathrm{c}$ \\
Beer & $20.2 \mathrm{f}$ & $36.8 \mathrm{c}$ \\
Red wine & $23.8 \mathrm{def}$ & $39.2 \mathrm{c}$ \\
White wine & $22.3 \mathrm{ef}$ & $38.8 \mathrm{c}$ \\
\hline
\end{tabular}

${ }^{2}$ Data are means of eight plants per treatment; mean separation in columns by Student-Newman-Keuls; 1 $\mathrm{cm}=0.3937$ inch

the wintertime. Based on these results, homeowners would plant bulbs in a normal hydroponic setting and allow initial root growth in water. After 7 to $10 \mathrm{~d}$ (more precisely, when plants are rooted, and new growth is 4 to 6 $\mathrm{cm}$ above the bulb), the water would be poured off and replaced with $4 \%$ to $5 \%$ alcohol, continuing to add more alcohol according to plant need. The alcohol source is widely flexible [gin, whiskey, rum, tequila, vodka, or schnapps (only at 3\% to $4 \%$ ethanol)], but beer and wine are not suitable. The preparation of the alcohol solution is critical, as toxicity begins between $5 \%$ and $10 \%$ ethanol.

The question remains as to the mechanism of root-zone alcohol as a suppressor of plant growth. There are two hypotheses, one based on direct cellular toxicity, the other based on a simple osmotic effect of the ethanol. Obviously, direct toxicity occurs at higher ethanol concentrations. Within the range of "useful" ethanol concentrations of $2 \%$ to $5 \%$, preliminary experiments we have conducted using sorbitol as a "non-metabolized" osmoticum support the latter hypothesis, but additional work will be needed for confirmation.

\section{Literature cited}

Land, L. 2005. Gin on the rocks, for bulbs. New York Times 17 Feb. 2005. 30 June 2005. <http://events.nytimes. com/2005/02/17/garden/17qna. html? ex $=1120276800 \&$ en $=$ abdba0639c $63 \mathrm{dl} 15 \& \mathrm{ei}=5070>$. 